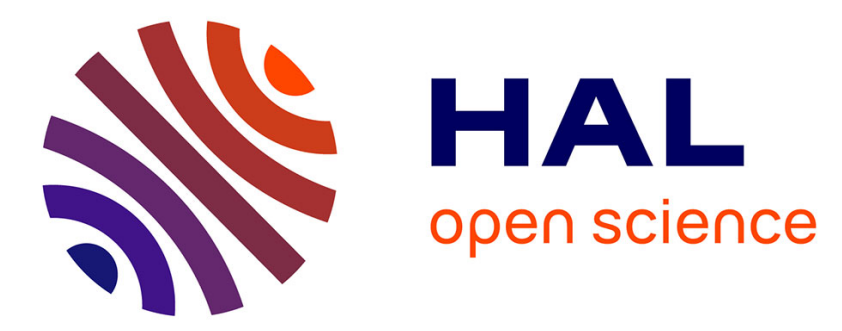

\title{
Design Issues of a Distance Learning Course on Business on the Internet
}

Krassen Stefanov, Svetoslav Stoyanov, Roumen Nikolov

\section{To cite this version:}

Krassen Stefanov, Svetoslav Stoyanov, Roumen Nikolov. Design Issues of a Distance Learning Course on Business on the Internet. Journal of Computer Assisted Learning, 1998, 14, pp.83-90. hal00190355

\section{HAL Id: hal-00190355 \\ https://telearn.archives-ouvertes.fr/hal-00190355}

Submitted on 23 Nov 2007

HAL is a multi-disciplinary open access archive for the deposit and dissemination of scientific research documents, whether they are published or not. The documents may come from teaching and research institutions in France or abroad, or from public or private research centers.
L'archive ouverte pluridisciplinaire HAL, est destinée au dépôt et à la diffusion de documents scientifiques de niveau recherche, publiés ou non, émanant des établissements d'enseignement et de recherche français ou étrangers, des laboratoires publics ou privés. 


\title{
Design Issues of a Distance Learning Course on Business on the Internet
}

\author{
Krassen Stefanov $^{1}$, Svetoslav Stoyanov ${ }^{2}$, and Roumen Nikolov ${ }^{1}$ \\ Department of Information Technologies ${ }^{1}$ \\ Faculty of Mathematics and Informatics, \\ Sofia University, 5, J. Bouchier St., \\ Sofia 1126, Bulgaria \\ krassen@fmi.uni-sofia.bg, roumen@fmi.uni-sofia.bg \\ Institute of Education and Science ${ }^{2}$ \\ Bul. Tzarigradsko Shosse 125, \\ Sofia 1113, Bulgaria \\ mp_stoyanov@edte.utwente.nl
}

\begin{abstract}
The paper presents the main design issues of a distance learning course on Business on the Internet. The instructional design is based on a learner centered instructional stratedy allowing learners get opportunity to construct their own knowledge while solving real business problems and transfer their knowledge to other learners. They learn autonomously taking the responsibility for their learning and following their individual cognitive styles, interests, preferences. The learners have access to the Internet being members of a global cooperatively learning community. The learning community involves students and tutors who collectively take responsibility for the design and evaluation of the course content and the teaching methods to be applied. Both students and tutors inhabit a virtual learning environment that offers different virtual places and services: virtual university, virtual enterprise, auditoriums, workshop rooms, cafes, libraries, etc., where students from different locations can meet, interact, learn and work together, as if they were face-to-face.
\end{abstract}

Keywords: telematics based distance learning, curriculum design, instructional design, virtual learning environments, virtual communities

\section{Introduction}

In Bulgaria, like in the other Central and Eastern European Countries(CEEC), there is an urgent need to turn around the existing companies and at the same time to create favorable conditions for emerging private enterprises that require better knowledge in economics, business, and company management. This makes economics, business and management education at organizations and at university level of utmost importance for the development of the country. However mass education could hardly be achieved without applying the methods and tools of the new educational technologies based on Communication and Information Technology(CIT). From the other side the CIT provides opportunities to set up and successfully run partly or purely virtual business organizations that could help the countries overcome the existing informational, economics, cultural, geographic and other barriers [2,5,7]. The people involved in the process of globalization and further internationalization of the business also needs appropriate training and continues support. The telematics based Distance Learning (DL) is considered as a possible answer of some of the new challenges for Bulgaria and the other CEEC.

Education and training in organizations is area where CIT is widely used. As working needs knowledge and skills, learning becomes an obligatory element of working. The needs, constrains, and technological alternatives of learning support at work differ from those of school learning[4]. For instance as the work situation is not static the workers should adapt themselves to new circumstances and working methods. This means that two separated support systems should be updated continuously - the system for work and the system for learning. The team learning approach supported by a collaboration network (hypergroupware) is considered as a successful strategy[3]. The concepts of learning while doing, just-in-time and justin-place learning applied by using Electronic Performance Support Systems (EPSS) and Computer 
Supported Collaborative Learning (CSCL) systems are dominant in learning at work place, together with the emerging CIT-based flexible and distance learning strategies for corporate and professional training based on the Internet and the Intranet concepts.

\section{Main course design principles}

Before designing the course a model for flexible and distance learning was developed[10,13]. The main principles and the most important charatecteristics of this model are determined by the choice of a learner centered instructional. The learner centered pedagogy prescribes that the learner does not receive readymade knowledge. He should discover and construct his knowledge which does not mean to reinvent it though. There are several other important characteristics:

- The learners participate in learning objectives formulation and take the responsibility for their activities. They can manage their own learning, cooperate with others, take part in negotiations and discussions[9]. This makes them more motivated, self-directed and looking for personal efficiency. The student - teacher relationships are democratic ones. The students can even choose their teachers.

- The students get opportunities to construct their knowledge while solving real problems and transfer their knowledge to other students. They learn autonomously taking the responsibility for their own learning and following their individual cognitive styles, interests, and preferences. The students learn how to learn. The theoretical basis for the constructivist learning are the theories of Bruner[1] and Piaget[11].

- The teachers are mostly facilitators, ensuring the right educational resources at the right time. They also diagnosis the students' problems, and help them any time when needed. The formative evaluation of students' achievements and evaluation based on project outcomes is dominant. The teachers might be assisted by students-mentors who would help them and other students in using software tools[12].

- The problems the students solve are formulated either by themselves or by the teacher and come from their everyday life and from the participants professional practice The students and the teacher cooperatively solve these problems. The project pedagogy based on the theory of John Dewey and William Kilpatrick and empowered by the CIT[8] is considered as an alternative of the lesson-based pedagogy.

- The space, time, equipment, and all teaching materials and information resources are used in an extremely flexible way. The curriculum and the teaching and learning processes are highly individualized. Different pathways, a wide choice over content and support for learning are offered to students who can progress with different speed.

Most of the mentioned principles give rise to some new developments both in educational science and in technology and provide the unique chance to fill in the gap between the scientific studies and the real educational practice. Among the most important recently developed learning paradigms and theories, derived or related to information technologies, is the cognitive flexibility theory[15].

Nowadays, with the advent of the networked multimedia and hypermedia an opportunity to gradually reform the existing print-based educational system appeared and it eventually would reside into a CITbased educational system[8]. During this transition the following educational principles could be realized in their full extent:

- As a subject of education we could consider not simply a student but a student with an access to the Internet and being a member of a global cooperatively learning community[13]. The learning community which involves both students and tutors who collectively take responsibility for the design and evaluation of the course content and the teaching methods to be applied. The learning community can afford applying very flexible ways of learning based on constant adjustment of the content, established regulations (internal procedures) and methods of teaching leading to active communication and adaptation to the individual learning needs.

- The interaction between students and teachers, as a way out of the information overload, could be organized both in a face-to-face manner and by using asynchronous and on-line computer conferences. Cooperative learning could be realized in a highly interactive (virtual) learning environment comprising computer support cooperative learning systems. The design principles of the learning environment 
would be based on asynchronous space and time, responsive environments, and virtual reconstruction[8]. Every student would have his own responsive CIT-based learning environment allowing communication with his peers, teachers, virtual friends, network servers, etc.

- Integration of education could be based on using virtual electronic libraries and subject-oriented clearinghouses containing multimedia resources. The students should optimize their work by navigating into educational resources and taking decisions what is appropriate and what is not. Learning to learn and critical thinking are becoming the most important educational outcomes not only for the best students, but for everyone studying in a CIT-based educational system.

- Activities of working on a project could be widely accepted and realized. Networked multimedia communication and the Computer Supported Cooperative Work (CSCW) systems would enable project teams working together independently of time and space. The teachers should facilitate students' inquiry, manage their learning process, and help them navigate in a shared global information space.

The course Business on the Internet could also follow a scenario combining the resource-based learning approach with individual learning. The teacher (facilitator) could be considered as a special type of resource. A repository of case studies and Group Decision Support Systems (GDSS) could be used for providing resources and on-going support for group role-playing and group decisionmaking. The informal discussion between learners could be considered as a special form of learning in so-called self-instructional groups formed by the virtual learning communities inhabiting a virtual learning environment.

\section{A Virtual learning environment}

The World Wide Web (WWW) is built around three main ideas: physically and geographically distributed documents, unambiguous location of distributed documents, and a uniform interface. The idea of uniform interface is especially powerful, because the user should not switch from one interface to another when using different data bases. The idea of uniform interface is central in the Intranet concept - using the Internet concepts and principles in organizations, creating institutional webs of information, applying learners modeling and intelligent Internet agents technology.

One of the main design principles of computer-based learning environments is the principle of interactivity[14]. The implementation of interactivity can be perceived as an art because it requires a comprehensive range of skills, including an understanding of the learner, a deep understanding of software engineering, deeper knowledge about the contemporary instructional design principles, and aesthetically designed multimedia interface. Development of effective interactive learning environments will motivate and engage the learner.

The most important characteristics of the contemporary Web-based learning environments is the availability of virtual places: auditoriums, workshop rooms, cafes, libraries, etc., where students from different locations can meet, interact, and work together, as if they were face-to-face.

A prototype of a Virtual Environment for Distance Education and Training (VEDET) was developed[10]. The VEDET (from a helicopter view) contains four types of learning organizations: a virtual university, a virtual school, a virtual enterprise, and a virtual language learning center.. It includes also a virtual student house as well as a number of virtual services, such as: a virtual library, a virtual exhibition and entertainment center, a virtual electronic publishing house, a virtual help desk, a distance education brokerage service, a virtual student assessment center, a virtual electronic document and software delivery service, a virtual course customization service, a virtual transportation service, a virtual liaison office, a virtual public arena, a virtual post office. The VEDET duplicates and extends some of the existing educational and training establishments and services and allows their better integration and enrichment. The kernel of the VEDET is the virtual university. The VEDET offers a comprehensive metaphor and terminology to be used both for human-computer interface and instructional design purposes. For instance when designing the Business on the Internet DL course we could plan that some of the instructional activities have to be carried out at the virtual university, e.g. in the virtual auditorium, in the virtual library, and in the seminar rooms, and the other - in the virtual enterprise, where the learners can apply 
what they have already learned, e.g. doing marketing research on the Internet. This approach gives also a paradigm for restructuring traditional education and training by complementing them with a virtual component.

\section{Curriculum development}

Although the course is based on an open syllabus, the curriculum development was done in accordance with some classical principles. The strategy for the curriculum development was rather deductive, based on the overall strategy applied in the whole project. The empirical data (analysis of other distance courses with the similar subject) and theoretical sources play a major role in the design process. All developed materials were published on the WWW and made available for all members of the project as well as for all researchers throughout the world for critical remarks and comments.

The curriculum could be described in terms of its goals, objectives, target audience, etc. According to the Tyler's rationale model[16,17] the curriculum planning should be a linear process. At the first place it involves formulation of the learning objectives used to indicate the expected learning outcomes after the period of instruction. Next the curriculum developers select the content and the activities that are appropriate to achieve the specified learning outcomes. Finally, a form of evaluation of the educational achievements of the individual learners is considered. Our approach combines the Tyler model with the Walker's naturalistic model[18]. A special group including subject experts (university teachers in business and economics), educational specialists and software developers was created. Following the Walker's model the group reached a consensus about the purpose, content, structure and strategies to be employed.

A modular approach was applied in the curriculum development. The course Business on the Internet is considered as an applied module of a CIT course that was devided into basic (introductory) module and applied modules. The introductory module of the CIT course aims at introducing the basic Internet services. Within this module the students master the Internet literacy and beyond. This part of the course helps students, that are novices in the Internet, to get comprehensive information about computer networks, the whole Internet and its applications. The business and economics module aims at illustrating how the basic information and communication technologies presented in the introductory module, could be used for doing business on the Internet.

It was decided that the content would be subdivided to the following three main themes:

- techological background - stressing on specific software and hardware applications, revising what students learned in the introductory module with respect to the application ares;

- applying CIT to business activities into the company (Intranet solutions) - corporate communications, human resources, education and training, administration, financing, manufacturing, customer services and support, goods and materials, etc.;

- applying CIT to business activities outside the company (Internet solutions) - advertising and marketing, banking and payment, stock exchange, selling and buying, legal issues, etc.

After the main themes of the content was agreed on, then the topics for the course outline were specified (see Appendix I).

\subsection{Course goals}

The students should learn how to set up a Business on the Internet and how to use Internet for their business - for communication, sales, marketing, research, human resource development and customer relations. The main goal of the course is to encourage students to set up their own learning direction, and to give them more control over the learning process. The final projects will serve as the most valuable output from the course. Students should demonstrate their ability to use specific skills and to participate in discussions.

As a result of this course, students will be able to:

- Apply methods of sell products and services via the Internet.

- Evaluate the quality of services and products offered on the Internet.

- Develop tools, methods and procedures for Internet business presence

- Do marketing research on World Wide Web (WWW). 
- Set up and use Intranet solutions

- Establish new buyer-seller relationships, e.g. links with clients, banks, other companies, etc.

\subsection{Instructional strategy}

The course is based on a combination of lectures, student presentations, self-learning, project work, and "case study" - based discussion. Students will have opportunities to learn from the best practice cases available on the Internet and to establishing their own learning agenda. Each student will have opportunities for immediate feedback. He will be assigned as an expert in a particular area, e.g. marketing, finance, selling, advertising, etc., and asked to develop his own personal presence on the WWW.

A scenario of DL could include the following components:

- registration - apart from an especially prepared application form the applicant can fill in relevant diagnostic instruments. The registration and diagnostic instruments will be delivered via ordinary mail, e-mail or WWW.

- introduction - the tutor introduces himself to learners, present the outline of course, timetable of activities, the system of evaluation, etc. It could be done in different modes: face-to-face, by asynchronous or on-line electronic conference.

- break down of ice - the tutor invites the participants in the virtual auditorium and initiates a mutual introducing to each other.

- announcements - the tutor announces where and how the learners can find available the learning resources attached to the course, e.g. in the virtual reading room, in the virtual library, in their personal virtual learning environments (the client part of VEDET) and also announces the place, the time and the topic of first working seminar.

Further the tutor can build his own teaching strategy by combining different teaching methods, models, and activities, e.g. :

- social interaction models (group investigation, jurisprudential model, social inquiry, T-group model)

- models based on the information processing metaphor (concept attainment, inductive model, inquiry training model, advance organizer model, developmental model

- personal source models (non-directive teaching, classroom meeting model, awareness training)

- models after Romiszowski (expositive classroom instruction, discovery classroom instruction, individual tutorial, group tutorial, seminar, workshop, open group discussion, resource-based learning systems, project-based learning systems, programmed self-instructional methods, the TWI method, instruction by example: demonstration, illustration and modeling, classical and operand conditioning, simulation techniques, case study method, role-playing, instructional games and simulation games)

- group dynamics methods (brainstorming, DACUM, laboratory training)

Each instructor should have opportunities to choose among the models and methods mentioned above and construct (similar to using Lego bricks) his own unique instructional design model by taking into account the individual characteristics of learners and problems being solved.

\subsection{Assignments}

Regular assignments (short cases to be solved) will be announced throughout the course. Simple individual tests could also be offered from time to time. In addition there is a set of projects that will help students apply their professional experience and shape out their learning experience. All projects require group work and network communication via hypermedia documents, as well as designing and implementing such documents.

\subsection{The target audience:}

Students in the MSc and MBA programs of Sofia University in economics, management, computer science and applied mathematics , as well as all other who is interested in the issues related to doing effective business on the Internet. Special interest is expected from the managers of small and medium size enterprises willing to incorporate the CIT in their business. 


\subsection{Teaching materials}

The teaching materials contain a Teachers Guide and a Student Package. The teachers guide deals with the methodology for distance learning. As a lot of aspects of distance learning derive from the traditional education, the guide puts more attention on the specifics of distance learning and particularly on the use of CIT as instructional media. The guide also describes activities which have to be performed during the development and implementation phase.

The student package contains a description of all resource learning materials, their URLs, and hard copies of some of them. The following types of Web based resource materials were prepared:

- Catalog of business and economics Web sites (Universities, Educational Centres, Government institutions, Companies, etc.)

- Electronic libraries containing electronic papers and books as well as different business cases to be studied by the students.

- Two printed books which could be used as students' readers.

The Internet resources were carefully structured according to the course outline and linked with other relevant electronic libraries and sources. This will make it possible in an easy way to develop and enrich the collected set of resources and to adapt it to different teachers and students needs.

\section{Implementation}

Two different learners pilot groups are envisaged: regular students and managers in small and medium size enterprises. The first group is very homogeneous and consists of students from the University of Sofia. The managers will participate in the course in a distance delivery mode. The course will be experimentally offered to selected learners from the other Copernicus partner countries. The course content will be flexibly linked with the students experience and will reflect the specifics of the Bulgarian situation. This will help learners participate more actively and autonomously in the learning process. During the pilot implementation the role of tutors will be taken by some of the university teachers who are also curriculum developers. They will also prepare the next phase of implementation when the course will be offered to a wider international audience.

\section{Evaluation}

For the course evaluation purposes the Kirkpatrick's four levels of training program evaluation will be used[6].

a) Reactions of trainees

The feedback about the level of satisfactory and difficulties experienced by the learners will be analysed.

b) Learners' achievements

The learners' achievements will be evaluated by using:

- a set of tests to evaluate the learning results in terms of achieving the specified goals in terms of skills and knowledge.

- the solutions of the business cases given to the learners;

- the final assignment (the course project) requiring practical implementation of the Internet tools in solving a business problem.

c) Work behaviour

The analysis of the transfer of learning results into real work behavior is a crucial point in the evaluation of the curriculum. This point will be specially observed in the pilot learning group of managers when they go back their real working environment.

d) Organisation's benefit

The organizational benefits of learning will be analyzed in the case of the pilot learning group of managers. It is expected that the organizations they manage should improve their performance in information 
retrieving, maintaining and distributing, and in everyday business application of CIT. The managers can also take part in the evaluation of organization performance and make the necessary changes supported by their course tutors.

In the course evaluation phase the following approaches will be used as well:

- critical commenting: some reviewers will go through the course and will offer their constructive criticism about fundamental matters of content, style and teaching strategy. The group of reviewers will include: subject-matter experts, tutors who are familiar with learners, researchers participating in the project, learners who have recently studied similar course. Two types of evaluation checklists will be offered: content evaluation checklist and evaluation teaching effectiveness checklist.

- developmental testing: it involves trying out a lesson on sample learners and revising it before publishing the final version. The developmental testing can be done in two main forms: distance delivery (or face-to-face) tryout and field trial.

All results in terms of learning achievements, teacher and learners satisfaction both by the courses and tools used and the transfer of learning will be analyzed and used for course improvement. A revised model of a flexible and distance learning system through telematics networks and an improved methodology for courseware development will be developed. These outcomes will be incorporated into the instructor manual, as well in the student learning resource materials package.

\section{Conclusions}

The course is expected to be included, after the validation phase, in the regular distance education programs at Sofia University and will be used for validation of the VEDET as well. The proposed research project is expected to help building technology-based bridges between businesses in the CEEC and EC countries. It also offers a model and for FDL that allows learners to acquire skills and knowledge at their own pace, to choose the location of study (at home, in the library, at school, etc.), to choose the time for the group sessions, to navigate in a modular curriculum by using flexible learning materials based on CIT. We expect a significant contribution to the development of CIT-based education in all participating countries and corresponding impact on the society .

\section{Acknowledgements}

The work is financially supported by the EU Copernicus COP1445 Project and also partly funded by the National Science Fund, Project No.I-502/95 and Sofia University Science Fund, Contract No. 147/95.

\section{References}

1. Bruner, J. S. (1960). Towards a Theory of Instruction. Harvard University Press, Cambridge.

2. Ellsworth, J., Ellsworth, M.(1995) Marketing on the Internet, John Wiley \& Sons

3. Farraro,A., Rogers, E. \& Geisler, C (1995), Team Learning through Computer Supported Collaborative Design, CSCL'95 Proceedings, Indiana University, Bloomington, October 1720

4. Favorin, M.(1995) Towards Computer Support for Collaborative Learning at Work: Six Requirements, CSCL'95 Proceedings, Indiana University, Bloomington, October 17-20

5. Hoffman, D. L., Novak, T. P., and Chatterjee P.(1996), Commercial Scenarios for the Web: Opportunities and Challenges, JCMC, V.1 No.3., Special Issue on Electronic CommerceKirkpatrick, D. (1975).

6. Kirkpatrick, D. (1975) Evaluating training programs. Madison, Wis. :ASTD.

7. Lynch D.C., Lundquist L. (1996), Digital Money, The New Era of Internet Commerce, John Wiley \& Sons, New York, USA

8. McClintock, R.(1992), Power and Pedagogy: Transforming Education through Information technology. Institute for Learning technologies, New York.

9. McConnel,D.(1995) A Methodology for Designing Post Graduate Professional Development Distant Learning CSCL Programmes, CSCL'95 Proceedings, Indiana University, Bloomington, October 17-20 
10. Nikolov R. \& Nikolova I. (1996), A Virtual Environment for Distance Education and Training, IFIP WG3.6 Working Conference "Collaborative Learning and Working with Telematics". Vienna, Sep. 2-4

11. Piaget, J. (1970), Science of Education and the Psychology of the Child. Longman, London.

12. Resta, P. (1995). Project CIRCLE: Student Mentors as a Strategy for Training and Supporting Teachers in the Use of Computer-Based Tools for Collaborative Learning, CSCL'95 Proceedings, Indiana University, Bloomington, October, p. 17-20.

13. Sendov Bl. (1996), Theme 1, Learners in a Global Knowledge Space: towards Global Wisdom (Plenary paper), Second Unesco International Congress on Education and Informatics (EI'96), July 1-5, Moscow.

14. Sims, R. (1995) Interactivity: A Forgotten Art? InTRO "Repository of IT Research”, http://129.7.160.78/InTRO.html

15. Spiro, R., Feltovitch, P., Jacobson, M. and Coulson, R. (1992) Cognitive Flexibility, Constructivism, and Hypertext: Random Access Instruction for Advanced Knowledge Acquisition in Ill-Structured Domains, In: T. Duffy \& D. Jonassen (Eds.) Constructivism and the Technology of Instruction, Hillsdale, Elbaum Associates.

16. Taba, H. (1962), Curriculum Development: Theory and Practice. Harcourt Brace \& World, New York.

17. Tyler, R. (1949), Basic Principles of Curriculum and Instruction. University of Chicago Press, Chicago.

18. Walker, D. (1971). A Naturalistic Model for Curriculum Development, School Review, 80(1), p. 51-65.

\section{Appendix I}

Business on the Internet - Course Content

$\underline{\text { Topics }}$

1. New information society (new kinds of work; new kinds of education; new kinds of entertainment; new kinds of communities; new morality).

2. Technological background (client/server computing; data warehousing; decision-support systems; desktop video; groupware; intranets; mobile computing; multimedia; object-oriented technologies; intelligent agents; wireless technologies;

3. Security and privacy (names and passwords; secure mail - PGP; public certificates; private certificates; problems with certificates; digital time stamps; identity and accountability; cryptography; electronic crimes).

4. Corporate management, documentation and administration (virtual meetings and conferences; reports, brochures, data sheets; management information systems; corporation's communications; electronic libraries).

5. Corporate financing (contracts; accounting and billing; budgets and forecasts; reporting).

6. Customer services and support (virtual help desk; electronic forms and questionnaires; electronic sales and distributions; policies and procedures; statistics and monitoring).

7. Human resources (job description and postings; staffing and recruitment; education and training; bonuses, compensations, benefits; organizational charts).

8. New paying systems and banking services on the Internet (the role of payment systems; payment and settlement systems; commerce and the Internet; Internet payments systems under development; policy and regulatory issues; transaction cost theory; industry value chains).

9. Advertising and marketing on the Internet (promotion; one-to-one asynchronous contacts; closing; transaction; fulfillment and thrust).

10. Selling and purchasing on the Internet (digital convergence; collapsing chains; shopping on the net; Internet malls; digital transactions and pricing; business transaction model - CyberCash).

11. Legal issues and public applications (digital signatures, copyright, online publishing; law on the Internet; computerized voting and electronic democracy; electronic taxpaying; electronic negotiations and legislation; civil rights, liberty and privacy). 
12. What next (online storefront; search agents; multinational companies; custom oriented chains; clients; service providers; technology-providing companies). 